\title{
The Effect of Myo-inositol Supplementation on the Prevention of Gestational Diabetes in Overweight Pregnant Women: a Randomized, Double-blind, Controlled Trial
}

\section{Sedighe Esmaeilzadeh}

Department of Obstetrics \& Gynecology, Infertility and Reproductive Health Research Center, Health Research Institute, Babol University of Medical Sciences

\section{Reza Ghadimi}

Department of Community Medicine, School of Medicine, Social Determinants of Health Research Center, Research Institute for Health, Babol University of Medical Sciences

\section{Sepideh Mashayekhamiri}

Student Committee Research, Babol University of Medical Sciences

Mouloud Agajani Delavar ( $\square$ moloodaghajani@yahoo.com )

Babol University of Medical Science https://orcid.org/0000-0001-6906-1440

\section{Zahra Basirat}

Department of Obstetrics \& Gynecology, Infertility and Reproductive Health Research Center, Health Research Institute, Babol University of Medical Sciences

\section{Research Article}

Keywords: Body Mass Index, Diabetes, Inositol, Overweight, Pregnancy

Posted Date: April 16th, 2021

DOl: https://doi.org/10.21203/rs.3.rs-260476/v1

License: (c) (i) This work is licensed under a Creative Commons Attribution 4.0 International License. Read Full License 


\section{Abstract}

Purpose: This study is striving to test the hypothesis that a low dosage of myo-inositol supplementation may decrease the likelihood of gestational diabetes in overweight, pregnant women.

Methods: A randomized, double-blind, controlled trial was performed on 60 eligible overweight, pregnant women at 12-14 weeks of gestation at two Iranian obstetric clinics. The participants were divided into two groups based on blocked randomization. The myo-inositol group, receiving $2000 \mathrm{mg}$ plus $200 \mu \mathrm{g}$ folic acid daily and the control group, receiving $400 \mu \mathrm{g}$ of folic acid daily from 14 - 24 gestational weeks. The occurrence of gestational diabetes was determined based on 75-g 2-hour oral glucose tolerance test (OGTT) at 24-28 gestational weeks, which was the primary outcome of the study. The secondary outcomes were: the evaluation of insulin therapy, insulin resistance, and lipid profile, gestational weight gain, as well as fetal and maternal outcomes.

Results: The incidence of gestational diabetes in myo-inositol group was noticeably minimized compared with that of the control group ( $\mathrm{RR} 0.29,95 \% \mathrm{Cl} 0.09-0.94, p=0.037$ ). There were no differences between the two groups in terms of fasting blood sugar, fasting insulin, HOMA-IR, insulin therapy, and triglyceride. There was no report of severe adverse drug reactions, either.

Conclusions: The absolute risk reduction and the "Number-Needed-to-Treat" for gestational diabetes were $26.8 \%(95 \% \mathrm{Cl}, 5.6-48)$ and $3.7(95 \% \mathrm{Cl}, 2.1-18.0)$, respectively. Hence, it can be concluded that approximately one out of every four overweight pregnant women receiving myo-inositol benefitted from its daily intake.

\section{Background}

Gestational diabetes, one of the most prevalent endocrine disorders during pregnancy, can be described as glucose intolerance, which occurs or is diagnosed first during pregnancy [1]. Its prevalence may vary depending on the dietary regimes, race, and use of different diagnostic methods [2]. The diagnosis of gestational diabetes is usually done through an oral glucose tolerance test (OGTT) in the second trimester between 24-28 weeks [3]. It is generally assumed that many risk factors can be associated with the incidence of gestational diabetes during pregnancy. Some of these factors are: being overweight, obese, advancing age, recurrent abortions, persistent glucosuria, the family history of diabetes, poly cystic ovarian syndrome, previous gestational diabetes, as well as gaining excessive weight during pregnancy $[4,5]$. Among the above-mentioned factors, pre pregnancy body mass index (BMI) could be attributed to such pregnancy complications as gestational diabetes and pregnancy-induced hypertension/ preeclampsia [6, 7]. Given the growing prevalence of obesity, polycystic syndrome, and the resulting increase in gestational diabetes, it is imperative to consider prophylactic strategies so as to prevent the unintended consequences of gestational diabetes among pregnant women $[8,9]$.

To date, various methods such as diet modification, exercise, life style changes, insulin therapy, and oral diabetes agents (metformin and glyburide) have been used to prevent gestational diabetes, but the 
efficacy of these methods has not yet been fully proved [10-13]. To this end, several clinical trials have already evaluated the effect of myo-inositol on the prevention of gestational diabetes, but the results have been inconsistent [14-16]. In a recent meta-analysis based on five clinical trial studies, Vitagliano et al. [17] found that taking $4000 \mathrm{mg}$ myo-inositol daily during pregnancy could serve as an effective alternative to improve glycemic homeostasis and minimize the risk of gestational diabetes. It is also deemed as a fresh approach for the prevention of gestational diabetes without any adverse effects. In addition, there are three other review articles demonstrating that there is a need for different doses of myo-inositol in order to evaluate their effects on pregnant women [18-20]. In light of these concerns, we performed a randomized, double-blind clinical trial to investigate the hypothesis that a low dose of myoinositol supplementation during the second trimester of pregnancy can decrease the likelihood of developing gestational diabetes in overweight pregnant women.

\section{Methods}

This study, a randomized, double-blind, controlled trial attempt, strove to investigate the impact of myoinositol supplementation on the prevention of gestational diabetes in overweight, pregnant women. The estimated sample size was established based on $50 \%$ reduction in the occurrence of gestational diabetes (primary outcome) with the alpha value of $80 \%$ (2-tailed alpha of 0.05 ) and the beta value of $20 \%$. The target sample size comprised approximately 30 subjects in each group, assuming an adverse reaction of $15 \%$ and an expected loss of $20 \%$ in the follow-up.

The myo-inositol group received the daily intake of $2000 \mathrm{mg}$ myo-inositol plus 200 micrograms folic acid from 14-24 gestational weeks [21]. The control group also received the daily intake of $400 \mu \mathrm{g}$ of folic acid from 14-24 gestational weeks. The diagnosis of gestational diabetes was done through 75-g 2-hour oral glucose tolerance test (OGTT) at $24-28$ gestation weeks. If a value was $\geq 92 \mathrm{mg} / \mathrm{dl}$ at 0 hours, $\geq 180$ $\mathrm{mg} / \mathrm{dl}$ at 1-hour, and $\geq 153 \mathrm{mg} / \mathrm{dl}$ at 2-hour, then it was regarded as diagnostic gestational diabetes [22].

Seventy six singleton, overweight, pregnant women (pre pregnancy BMI $\geq 25$ and $<30 \mathrm{~kg} / \mathrm{m}^{2}$ ) [23], aged 18-40, were enrolled at their first visits (the first trimester pregnancy). They were chosen from two clinics of gynecology and obstetrics in Babol. The study was carried out over the period between April 2018 and February 2020. Having elucidated the procedure and the possible side effects of myo-inositol supplement, the researchers gave the written informed consents to the participants to fill out. The women with diabetes, a history of hypertension, cardiovascular diseases, current smoking or drinking habits were excluded from the study. Those who had experienced the death of family members or received corticosteroids during pregnancy were also excluded from the study. Moreover, the eligible participants' attributes, including their age, parity, family history of diabetes, neck circumference, the self-reported prepregnancy $\mathrm{BMI}$, and the pre-pregnancy waist circumference were meticulously recorded. Blood samples were also collected after an overnight fasting of 10-12 hours in order to measure fasting glucose, fasting insulin, total cholesterol, and triglyceride. The serum glucose and lipids were defined based on commercially available kits (Pars Azmoon, Tehran, IR Iran). Serum insulin concentration was done through Elisa kit (DRG Diagnostics, Marburg, Germany). The homeostasis model assessment-estimated 
insulin resistance (HOMA-IR) value was calculated through the bellowing formula: fasting insulin in $\mu \mathrm{U} / \mathrm{mL}$ multiply fasting glucose in $\mathrm{mg} / \mathrm{dL}$ divided by 405 . Finally, sixty eligible women were randomly assigned to either a control or a myo-inositol group based on the blocked randomization with a block size of 4 , which was done through a computer-generated random numbers. The randomization was conducted at both clinics of gynecology and obstetrics. Random number listing and concealment allocation were conducted through no clinical investigations in order to guarantee that each subject had an equal chance of being selected for the intervention group or the control group. The sachets containing $2000 \mathrm{mg}$ of a myo-inositol supplementation powder (LO.LI. Pharma ,Rome, Italy, Inofulic) and $200 \mu \mathrm{g}$ of folic acid for the intervention group and the sachets containing $400 \mu \mathrm{g}$ of folic acid for the control group were prepared by a pharmacist. It should be mentioned that the sachets for the control group were identical in color, flavor and texture. The Pharmacist sealed all the envelopes and assigned a number to each envelope. Each participant was provided with seventy sachets for a total of 10 weeks. Telephone call reminders were made every week to those receiving the sachets. All pregnant women were requested to bring the remaining sachets during their prenatal visits to monitor their compliance with the procedure of the study. The final compliance was assessed at the time of OGTT through counting sachets. If $90 \%$ of sachets had been actually taken, the individual's compliance was acceptable. All women were advised not to take other vitamins or supplements except for the daily intake of $60 \mathrm{mg}$ iron supplement. The participants, the researcher collecting data, and the person analyzing the data were all blinded to treatment allocation. The break of the blinding codes was done by the pharmacist after data analysis.

The incidence of gestational diabetes (abnormal oral glucose tolerance test) at 24-28 gestational weeks was the primary outcome of this study. In addition, the secondary outcomes were: the evaluation of insulin resistance and lipid profile, insulin therapy, inappropriate gestational weight gain, caesarean section, pregnancy-induced hypertension / pre-eclampsia, preterm delivery ( $<37$ gestational weeks), fetal macrosomia ( $>4 \mathrm{~kg}$ ), shoulder dystocia, neonatal respiratory distress syndrome (RDS), and neonatal intensive care unit (NICU) admissions. The occurrence of adverse drug effects caused by intervention such as the presence of uterine contractions, headache, nausea / vomiting, diarrhea, tiredness, and flatulence were all assessed during follow-up visits.

Two participants, one in each group, were excluded from the study during the follow up due to their midtrimester abortions. Also, there were two losses in the follow-up phase in myo-inositol group due to lack of desire to continue the study (one woman) and severe side effect (on women with headache). Finally, 27 women in myo-inositol and 29 women in the control group completed the study (Fig. 1).

The data analysis was performed using SPSS statistics version 20 (IBM, Chicago, IL). All continuous variables were normally distributed. T-test was used to compare the means of the two groups. The primary and secondary outcomes were assessed through a multiple regression approach for the analysis of covariance (ANCOVA) for parametric parameters and relative risk (RR) with $95 \%$ confidence intervals (Cl) for non-parametric using MedCalc ${ }^{\circledR}$ (https://www.medcalc.org/calc/relative_risk.php). A value of $\mathrm{P}<$ 0.05 was regarded as statistically significant. 


\section{Results}

It is worth mentioning that the attributes of the two groups were akin in terms of maternal age, nulliparity, the family history of diabetes, the pre-pregnancy BMI, neck circumference, pre-pregnancy waist circumference, fasting insulin, fasting glucose, the total cholesterol, triglyceride, and HOMA-IR at baseline (Table 1). There was only one case in myo-inositol group who reported an adverse reaction to drug intake, but there was no report of adverse reaction from the control group. The incidence of gestational diabetes in myo-inositol group was $11.1 \%$ compared with that of $37.9 \%$ in the control group, RR $0.29(95 \% \mathrm{Cl} 0.09-$ $0.94)(p=0.037)$. There was only one case with gestational diabetes in the myo-inositol group who was treated with insulin, whereas there were five in the control group. It is worth mentioning that the difference between the two groups in terms of insulin therapy was not statistically significant. The occurrence of the inappropriate gestational weight gain in myo-inositol group was significantly lower than that of the control group, $40.8 \%$ versus $75.9 \%$, RR $0.57(95 \% \mathrm{Cl} 0.35-0.95)(p=0.038)$. It must be noted that the rate of caesarean section and the occurrence of PIH or pre-eclampsia, preterm delivery, fetal macrosomia, RDS, and NICU admissions were similar in both groups. No evidence of shoulder dystocia was found in both groups, either (Table 2). Furthermore, a statistically significant increase in total cholesterol and triglyceride was observed in both groups after the intervention $(p<0.0001)$. There was, however, no significant mean difference in triglyceride between the two groups. As far as total cholesterol is concerned, there was a significant mean difference between the two groups (myo-inositol group placebo group) $-24.40(95 \% \mathrm{Cl}-40.85$ to -7.96$)(p=0.004)$. Despite the fact that the average HDL cholesterol significantly increased in myo-inositol group $(p=0.029)$, no significant mean difference was observed between the two groups. There was no difference reported between the two groups in terms of FBS, fasting insulin, and HOMA-IR (Table 3). Fortunately, no sever adverse drug reactions were reported by pregnant women. 
Table 1

Baseline characteristics of the pregnant women in Both Groups

\begin{tabular}{|c|c|c|}
\hline \multirow[t]{2}{*}{ Characteristic } & $\begin{array}{l}\text { Myo-inositol group } \\
(\mathrm{N}=27)\end{array}$ & $\begin{array}{l}\text { Control group } \\
(\mathrm{N}=29)\end{array}$ \\
\hline & Mean \pm SD & Mean \pm SD \\
\hline Age (years) & $27.8 \pm 4.2$ & $29.3 \pm 4.4$ \\
\hline Nulliparity, n (\%) & $15(55.6)$ & $16(55.2)$ \\
\hline Family history of diabetes, $\mathrm{n}(\%)$ & $8(29.6)$ & $11(37.9)$ \\
\hline Pre- Prepregnancy BMla $\left(\mathrm{kg} / \mathrm{m}^{2}\right)$ & $27.3 \pm 1.8$ & $26.9 \pm 1.9$ \\
\hline Neck circumference $(\mathrm{cm})$ & $33.1 \pm 2.1$ & $33.3 \pm 1.8$ \\
\hline Pre- Prepregnancy $W C^{b}(\mathrm{~cm})$ & $100.3 \pm 7.9$ & $101.8 \pm 8.3$ \\
\hline Fasting glucose $(\mathrm{mg} / \mathrm{dL})$ & $10.8 \pm 6.9$ & $12.7 \pm 5.0$ \\
\hline Fasting insulin $(\mu \mathrm{U} / \mathrm{mL})$ & $84.0 \pm 6.8$ & $85.2 \pm 6.5$ \\
\hline HOMA-IR* & $2.3 \pm 1.6$ & $2.7 \pm 1.0$ \\
\hline Total cholesterol (mg/dL) & $188.4 \pm 37.3$ & $173.3 \pm 34.3$ \\
\hline Triglyceride(mg/dL) & $128.8 \pm 50.4$ & $155.8 \pm 59.3$ \\
\hline
\end{tabular}


Table 2

Primary and secondary outcomes among pregnant women in Both Groups

\begin{tabular}{|c|c|c|c|c|}
\hline \multirow[t]{2}{*}{ Outcome } & $\begin{array}{l}\text { Myo-inositol } \\
\text { group } \\
(\mathrm{N}=27)\end{array}$ & $\begin{array}{l}\text { Control } \\
\text { group } \\
(\mathrm{N}=29)\end{array}$ & $\begin{array}{l}\text { Relative risk } \\
\text { (RR) } \\
(95 \% \mathrm{Cl})\end{array}$ & \multirow[t]{2}{*}{$p$} \\
\hline & $N(\%)$ & $\mathbf{N}(\%)$ & $(95 \% \mathrm{Cl})$ & \\
\hline Gestational diabetes diagnosis & $3(11.1)$ & $11(37.9)$ & $0.29(0.09,0.94)$ & 0.038 \\
\hline Insulin therapy & $1(3.7)$ & $5(17.2)$ & $0.21(0.03,1.72)$ & 0.147 \\
\hline $\begin{array}{l}\text { Inappropriate gestational weight } \\
\text { gain }\end{array}$ & $11(40.8)$ & $22(75.9)$ & $0.57(0.35,0.95)$ & 0.032 \\
\hline Caesarean section & $17(63.0)$ & $19(65.5)$ & $0.96(0.65,1.42)$ & 0.842 \\
\hline $\mathrm{PIH}^{\mathrm{a}}$ or pre-Eclampsia & $0(0)$ & $1(3.4)$ & $0.36(0.02,8.41)$ & 0.523 \\
\hline Preterm delivery & $2(7.4)$ & $3(10.3)$ & $0.72(0.13,3.96)$ & 0.702 \\
\hline Fetal macrosomia (> 400kg) & $2(7.4)$ & $2(6.9)$ & $1.07(0.16,7.10)$ & 0.941 \\
\hline Shoulder dystocia & 0 & 0 & $\begin{array}{l}1.07(0.02 \\
52.19)\end{array}$ & 0.972 \\
\hline $\mathrm{RDS}^{\mathrm{b}}$ & 0 & $2(6.9)$ & $0.21(0.10,4.27)$ & 0.313 \\
\hline $\mathrm{NICU}_{\text {admissions }}{ }^{\mathrm{C}}$ & $2(7.4)$ & $5(17.2)$ & $\begin{array}{l}0.43(0.090 \\
2.03)\end{array}$ & 0.287 \\
\hline
\end{tabular}


Table 3

Comparisons of oral glucose tolerance test, insulin sensitivity, and lipid characteristics in pregnant women before and after intervention (24-28 Weeks of Gestation) in both groups

\begin{tabular}{|c|c|c|c|c|c|c|c|c|}
\hline \multirow[t]{3}{*}{ Outcome } & Myo-inc & itol grou & $(N=27)$ & \multicolumn{3}{|c|}{ Control group $(\mathrm{N}=29)$} & \multirow{3}{*}{$\begin{array}{l}\text { Mean } \\
\text { Difference } \\
(95 \% \mathrm{Cl}) \\
\text { Myo-inositol } \\
\text { - Control }\end{array}$} & \multirow[t]{3}{*}{$P$} \\
\hline & Before & After & $P$ & Before & After & $P$ & & \\
\hline & $\begin{array}{l}\text { Mean } \\
\pm S D\end{array}$ & $\begin{array}{l}\text { Mean } \\
\pm S D\end{array}$ & & $\begin{array}{l}\text { Mean } \\
\pm \text { SD }\end{array}$ & $\begin{array}{l}\text { Mean } \\
\pm S D\end{array}$ & & & \\
\hline $\begin{array}{l}\mathrm{FBS}^{\mathrm{a}} \\
(\mathrm{mg} / \mathrm{dL})\end{array}$ & $\begin{array}{l}84.0 \pm \\
6.8\end{array}$ & $\begin{array}{l}82.7 \pm \\
7.8\end{array}$ & 0.480 & $\begin{array}{l}85.2 \pm \\
6.5\end{array}$ & $\begin{array}{l}83.1 \pm \\
10.4\end{array}$ & 0.305 & $\begin{array}{l}-0.09(-5.01 \\
4.84)\end{array}$ & 0.972 \\
\hline $\begin{array}{l}\text { Fasting } \\
\text { insulin } \\
(\mu \mathrm{U} / \mathrm{mL})\end{array}$ & $\begin{array}{l}10.8 \pm \\
6.9\end{array}$ & $\begin{array}{l}12.3 \pm \\
6.6\end{array}$ & 0.210 & $\begin{array}{l}12.7 \pm \\
5.0\end{array}$ & $\begin{array}{l}12.2 \pm \\
4.8\end{array}$ & 0.646 & $\begin{array}{l}0.95(-1.81 \\
3.73)\end{array}$ & 0.493 \\
\hline HOMA-IR & $\begin{array}{l}2.3 \pm \\
1.6\end{array}$ & $\begin{array}{l}2.6 \pm \\
1.5\end{array}$ & 0.298 & $\begin{array}{l}2.7 \pm \\
1.0\end{array}$ & $\begin{array}{l}2.5 \pm \\
1.1\end{array}$ & 0.622 & $\begin{array}{l}0.19(-0.45 \\
0.83)\end{array}$ & 0.550 \\
\hline $\begin{array}{l}\text { Total } \\
\text { cholesterol } \\
(\mathrm{mg} / \mathrm{dl})\end{array}$ & $\begin{array}{l}188.4 \\
\pm 37.3\end{array}$ & $\begin{array}{l}217.7 \\
\pm 47.3\end{array}$ & $\begin{array}{l}<.0001 \\
0.00\end{array}$ & $\begin{array}{l}173.3 \\
\pm 34.3\end{array}$ & $\begin{array}{l}229.3 \\
\pm 36.2\end{array}$ & $\begin{array}{l}< \\
0.0001\end{array}$ & $\begin{array}{l}-24.40(-40.85 \\
-7.96)\end{array}$ & 0.004 \\
\hline $\begin{array}{l}\text { Triglyceride } \\
\text { (mg/dL) }\end{array}$ & $\begin{array}{l}128.8 \\
\pm 50.4\end{array}$ & $\begin{array}{l}209.4 \\
\pm 87.5\end{array}$ & $\begin{array}{l}< \\
0.0001\end{array}$ & $\begin{array}{l}155.8 \\
\pm 59.3\end{array}$ & $\begin{array}{l}273.2 \\
\pm 22.9\end{array}$ & 0.007 & $\begin{array}{l}-34.05(- \\
123.78,55.68)\end{array}$ & 0.450 \\
\hline $\mathrm{HDL}(\mathrm{mg} / \mathrm{dL})$ & $\begin{array}{l}55.3 \pm \\
11.1\end{array}$ & $\begin{array}{l}65.9 \pm \\
23.7\end{array}$ & 0.029 & $\begin{array}{l}57.6 \pm \\
12.1\end{array}$ & $\begin{array}{l}60.2 \pm \\
11.7\end{array}$ & 0.153 & $\begin{array}{l}5.71(-4.28 \\
15.69)\end{array}$ & 0.257 \\
\hline
\end{tabular}

\section{Discussion}

The present study found that the daily intake of $2000 \mathrm{mg}$ of my-oinositol supplement plus $200 \mu \mathrm{g}$ of folic acid during the second trimester of pregnancy could decrease the incidence of the gestation diabetes among the overweight, pregnant women. Our finding aligns with the result of a previous study, administrating the same myo-inositol supplement twice a day in both the second and third trimesters of pregnancy and reported a noticeable reduction for gestational diabetes [23]. In a similar vein, Facchinetti et al. [24] reported that gestational diabetes was reduced in overweight/obese pregnant women by taking $2000 \mathrm{mg}$ of myo-Inositol plus $200 \mu \mathrm{g}$ of folic acid twice a day between the 11th week of pregnancy and delivery, $14.0 \%$ compared with $33.6 \%$, respectively. Continuing the same line of research, D'Anna et al. [25] conducted a study in which obese pregnant women took the same dosage (total 4000 mg myo-Inositol plus $200 \mu \mathrm{g}$ of folic acid/daily) for the same period of time (in both second and third trimester). The results demonstrated that the likelihood of gestational diabetes was minimized in the myo-inositol group compared with that of the control group. While the previous studies claimed that the administration of 
myo-inositol from the early stages of pregnancy could decrease the occurrence of gestational diabetes in overweight women [26], our finding depicted that a lower dose of myo-inositol could be used during the second trimester to maximize the likelihood of gestational diabetes.

In the present study, insulin therapy started when the glycemic status of pregnant women was not under control. We did not find a significant decrease in insulin as a result of insulin therapy through myoinositol. Also, the absolute risk increase for insulin therapy was not significant. That could be attributed to the fact that the participants did not receive myo-inositol during the third trimester of pregnancy. We assume that receiving myo-inositol with low-glycemic diet during the third trimester of the pregnancy could be a more effective strategy to control glycemic women with gestational diabetes. Contrary to this assumption, Matarrelli et al. reported that insulin therapy was not reduced with the administration of a higher dosage of myo-inositol during the entire period of pregnancy [15]. In light of these concerns, we recommend that it is urgent to conduct future trials with larger samples to assess as to whether taking myo-inositol once a day during the second trimester of pregnancy can prevent gestational diabetes.

It is thought that the interaction between adipokynes with visceral tissue in overweight women may result in insulin resistance. In addition, it is generally assumed that there are insulin resistance, hyperinsulinemia, and decreased insulin sensitivity during the third trimester of pregnancy $[27,28]$. Despite the fact that several studies have already shown that myo-inositol could be the major factor for the decrease of HOMA-IR and the increase of insulin resistance [2, 29, 25], we did not find any significant decrease in HOMA-IR in our study. These results also revealed that myo-inositol supplementation could not decrease lipid profiles. This dosage of myo-inositol, taken during the second trimester of pregnancy only, may be inadequate to decrease HoMA-IR, insulin resistance and lipid profiles in overweight pregnant women. This study was an attempt to investigate the maternal weight gain during pregnancy. The results demonstrated that myo-inositol may mitigate the occurrence of inappropriate maternal weight gain during pregnancy. Our finding is congruous with the result of a research study having a similar effect on weight gain [24].

Although the occurrence of gestational diabetes was reduced in our study, which is a significant achievement for us, we did not manage to achieve better caesarean section rate, $\mathrm{PIH}$ or pre-Eclampsia, preterm delivery, fetal macrosomia, RDS, and NICU admissions through myo-inositol. Nonetheless, the adverse outcomes such as RDS and NICU admissions were very small. In myo-inositol group, we did not observe any PIH or pre-Eclampsia, which was probably due to small sample size. Furthermore, the rate of cesarean section was very high in both groups, and all fetal macrosomic births were delivered by cesarean section in this study. It must be noted that shoulder dystocia was not observed in both groups, either.

It is worth mentioning that no severe adverse drug reactions caused by myo-inositol were reported by pregnant women. Only one pregnant woman reported headaches, who was subsequently excluded from the study, but it had nothing to do with myo-inositol. A major strength of this study is its randomized, double-blind design, while all the previous studies were open-label trials. In addition, our study was the 
first study of its kind to have used relatively low myo-inositol during the preliminary weeks of pregnancy. Furthermore, all participants had access to the main researcher through telephone $24-\mathrm{h}$, and the main researcher could frequently contact them to monitor their compliance with the aims of the study.

One major limitation of our study was our limited power to detect the adverse birth outcomes and the side-effect of myo-inositol due to small sample size. The primary goal of our study was to investigate the effect of myo-inositol supplementation on gestational diabetes. Finally, there is an urgent need for a more comprehensive study to assess the risk of adverse birth outcomes and the side-effects of myo-inositol on overweight pregnant women.

\section{Conclusions}

The absolute risk reduction and "Number-Needed-to-Treat" for gestational diabetes were $26.8 \%(95 \% \mathrm{Cl}$, 5.6-48 and $3.7(95 \% \mathrm{Cl}, 2.1-18.0)$, respectively. Therefore, approximately one out of four overweight pregnant women receiving myo-inositol benefited from it. Myo-inositol was also found to be effective in decreasing inappropriate weight gain during pregnancy. Nonetheless, this study, as far as we know, was the first randomized, double-blind, clinical trial to investigate the effect of a low dosage of myo-inositol supplementation on the occurrence of gestational diabetes in overweight pregnant women. The results showed that taking low dosages of myo-inositol supplementation during the second trimester of pregnancy could be an effective strategy for the prevention of gestational diabetes. More investigations with larger samples of overweight pregnant women are required to confirm these findings, though.

\section{Declarations}

\section{Acknowledgements}

The authors are genuinely grateful to Iranian pregnant women for their participation in this study. We also acknowledge the staff at the health centers for their cooperation throughout the implementation phase of this study.

\section{Funding}

Not applicable.

\section{Availability of data and material}

The datasets used during this study are available from the corresponding author on reasonable request.

\section{Authors' contributions}

MAD, SE, and RG developed the idea for research and formulated the research proposal. SM, SE, and ZB collected the data. The data analysis was done by MAD. MAD and RG prepared the manuscript. All authors proofread and approved the final manuscript. 


\section{Ethics approval and consent to participate}

The study was approved by the ethics committee of Babol University of Medical Science (Ethic ID: MUBABOL.HRI.REC.1396.82), and was also registered in Iranian Registry of Clinical Trials (IRCTID: IRCT20160208026446N2) by Mouloud Agajani Delavar. Registered 14 December 2017, https://en.irct.ir/trial/21922.

\section{Consent for publication}

Not applicable.

\section{Footnotes}

Publisher's Note

\section{Competing interests}

The authors report no conflicts of interest. There was no provision of myo-inositol sachets by Italfarmaco SpA.

\section{References}

1. Alfadhli EM (2015) Gestational diabetes mellitus. Saudi Med J 36 (4):399-406. doi:10.15537/smj.2015.4.10307

2. Corrado F, D'Anna R, Di Vieste G, Giordano D, Pintaudi B, Santamaria A, Di Benedetto A (2011) The effect of myoinositol supplementation on insulin resistance in patients with gestational diabetes. Diabet Med 28 (8):972-975. doi:10.1111/j.1464-5491.2011.03284.x

3. Agarwal MM (2015) Gestational diabetes mellitus: An update on the current international diagnostic criteria. World J Diabetes 6 (6):782-791. doi:10.4239/wjd.v6.i6.782

4. Proceedings of the 4th International Workshop-Conference on Gestational Diabetes Mellitus. Chicago, Illinois, USA. 14-16 March 1997 (1998). Diabetes Care 21 Suppl 2:B1-167

5. Schwartz N, Nachum Z, Green MS (2016) Risk factors of gestational diabetes mellitus recurrence: a meta-analysis. Endocrine 53 (3):662-671. doi:10.1007/s12020-016-0922-9

6. Doherty DA, Magann EF, Francis J, Morrison JC, Newnham JP (2006) Pre-pregnancy body mass index and pregnancy outcomes. Int J Gynaecol Obstet 95 (3):242-247. doi:10.1016/j.ijgo.2006.06.021

7. Raatikainen K, Heiskanen N, Heinonen S (2006) Transition from overweight to obesity worsens pregnancy outcome in a BMI-dependent manner. Obesity (Silver Spring) 14 (1):165-171. doi:10.1038/oby.2006.20

8. Moses RG, Cefalu WT (2016) Considerations in the Management of Gestational Diabetes Mellitus: "You Are What Your Mother Ate!". Diabetes Care 39 (1):13-15. doi:10.2337/dci15-0030 
9. Esmaeilzadeh S, Delavar MA, Amiri M, Khafri S, Pasha NG (2014) Polycystic ovary syndrome in Iranian adolescents. Int J Adolesc Med Health 26 (4):559-565

10. Camelo Castillo W, Boggess K, Sturmer T, Brookhart MA, Benjamin DK, Jr., Jonsson Funk M (2015) Association of Adverse Pregnancy Outcomes With Glyburide vs Insulin in Women With Gestational Diabetes. JAMA Pediatr 169 (5):452-458. doi:10.1001/jamapediatrics.2015.74

11. Faraci M, Di Prima FA, Valenti O, Hyseni E, Monte S, Giorgio E, De Domenico R (2011) Treatment of gestational diabetes: oral hypoglycemic agents or insulin? J Prenat Med 5 (3):63-64

12. Feig DS, Moses RG (2011) Metformin therapy during pregnancy: good for the goose and good for the gosling too? Diabetes Care 34 (10):2329-2330. doi:10.2337/dc11-1153

13. Negrato CA, Mattar R, Gomes MB (2012) Adverse pregnancy outcomes in women with diabetes. Diabetology \& metabolic syndrome 4 (1):41. doi:10.1186/1758-5996-4-41

14. Farren M, Daly N, McKeating A, Kinsley B, Turner MJ, Daly S (2017) The Prevention of Gestational Diabetes Mellitus With Antenatal Oral Inositol Supplementation: A Randomized Controlled Trial. Diabetes Care 40 (6):759-763. doi:10.2337/dc16-2449

15. Matarrelli B, Vitacolonna E, D'Angelo M, Pavone G, Mattei PA, Liberati M, Celentano C (2013) Effect of dietary myo-inositol supplementation in pregnancy on the incidence of maternal gestational diabetes mellitus and fetal outcomes: a randomized controlled trial. J Matern Fetal Neonatal Med 26 (10):967972. doi:10.3109/14767058.2013.766691

16. Rogozinska E, Chamillard M, Hitman GA, Khan KS, Thangaratinam S (2015) Nutritional manipulation for the primary prevention of gestational diabetes mellitus: a meta-analysis of randomised studies. PLoS One 10 (2):e0115526. doi:10.1371/journal.pone.0115526

17. Vitagliano A, Saccone G, Cosmi E, Visentin S, Dessole F, Ambrosini G, Berghella V (2019) Inositol for the prevention of gestational diabetes: a systematic review and meta-analysis of randomized controlled trials. Arch Gynecol Obstet 299 (1):55-68

18. Crawford TJ, Crowther CA, Alsweiler J, Brown J (2015) Antenatal dietary supplementation with myoinositol in women during pregnancy for preventing gestational diabetes. Cochrane Database Syst Rev 2015 (12):CD011507-CD011507. doi:10.1002/14651858.CD011507.pub2

19. Nordio M, Proietti E (2012) The combined therapy with myo-inositol and D-chiro-inositol reduces the risk of metabolic disease in PCOS overweight patients compared to myo-inositol supplementation alone. Eur Rev Med Pharmacol Sci 16 (5):575-581

20. Zhang H, Lv Y, Li Z, Sun L, Guo W (2019) The efficacy of myo-inositol supplementation to prevent gestational diabetes onset: a meta-analysis of randomized controlled trials. J Matern Fetal Neonatal Med 32 (13):2249-2255. doi:10.1080/14767058.2018.1428303

21. Croze ML, Soulage CO (2013) Potential role and therapeutic interests of myo-inositol in metabolic diseases. Biochimie 95 (10):1811-1827. doi:10.1016/j.biochi.2013.05.011

22. American Diabetes Association. Diagnosis and classification of diabetes mellitus (2011). Diabetes Care 34 Suppl 1:S62-69. doi:10.2337/dc11-S062 
23. Metzger BE, Lowe LP, Dyer AR, Trimble ER, Chaovarindr U, Coustan DR, Hadden DR, McCance DR, Hod M, McIntyre HD, Oats JJ, Persson B, Rogers MS, Sacks DA (2008) Hyperglycemia and adverse pregnancy outcomes. N Engl J Med 358 (19):1991-2002. doi:10.1056/NEJMoa0707943

24. Facchinetti F, Pignatti L, Interdonato ML, Neri I, Bellei G, D'Anna R (2013) Myoinositol supplementation in pregnancies at risk for gestational diabetes. Interim analysis of a randomized controlled trial (RCT). Am J Obstet Gynecol 208 (1):S36

25. D’Anna R, Di Benedetto A, Scilipoti A, Santamaria A, Interdonato ML, Petrella E, Neri I, Pintaudi B, Corrado F, Facchinetti F (2015) Myo-inositol supplementation for prevention of gestational diabetes in obese pregnant women: A randomized controlled trial. Obstetrics and gynecology 126 (2):310-315. doi:10.1097/aog.0000000000000958

26. D'Anna R, Scilipoti A, Giordano D, Caruso C, Cannata ML, Interdonato ML, Corrado F, Di Benedetto A (2013) myo-Inositol supplementation and onset of gestational diabetes mellitus in pregnant women with a family history of type 2 diabetes: a prospective, randomized, placebo-controlled study. Diabetes Care 36 (4):854-857. doi:10.2337/dc12-1371

27. Hadden DR, McLaughlin C Normal and abnormal maternal metabolism during pregnancy. In: Seminars in Fetal and Neonatal Medicine, 2009. vol 2. Elsevier, pp 66-71

28. Celentano C, Matarrelli B, Pavone G, Vitacolonna E, Mattei PA, Berghella V, Liberati M (2018) The influence of different inositol stereoisomers supplementation in pregnancy on maternal gestational diabetes mellitus and fetal outcomes in high-risk patients: a randomized controlled trial. J Matern Fetal Neonatal Med:1-9. doi:10.1080/14767058.2018.1500545

29. Fraticelli F, Celentano C, Zecca IA, Di Vieste G, Pintaudi B, Liberati M, Franzago M, Di Nicola M, Vitacolonna $\mathrm{E}$ (2018) Effect of inositol stereoisomers at different dosages in gestational diabetes: an open-label, parallel, randomized controlled trial. Acta Diabetol 55 (8):805-812. doi:10.1007/s00592018-1157-4

\section{Figures}




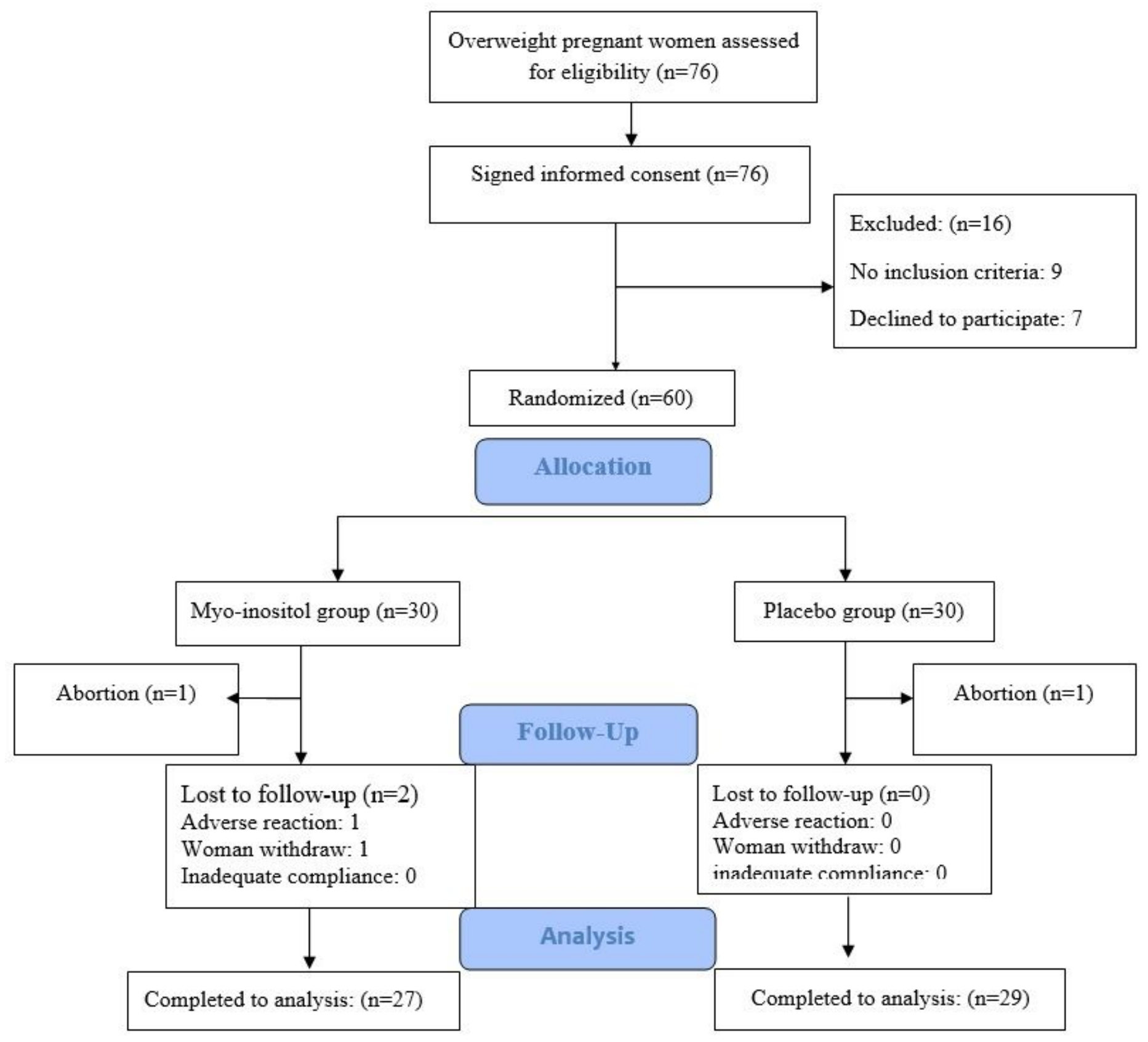

Figure 1

Consort Fellow diagram of the participants 